\title{
A lesson at the bedside
}

In treatment, when you come across resistance, let your hands become diviners, moving past the body's alibis, finding ruin where once there was only peace: here, healing happens. For some, a touch will do the trick. For others, comfort only comes in finding pain reflected in the blues of an old jazz piano, the grit of a grainy photograph, or in the delicate neck of a paper swan and, suddenly, recognizing it as their own.

\section{Emily Swinkin}

Second-year medical student

Queen's University

Kingston, Ont.

"A lesson at the bedside" won second prize in the poetry category of the 2012 ARS Medica and CMAJ Humanities Poetry and Prose contest.

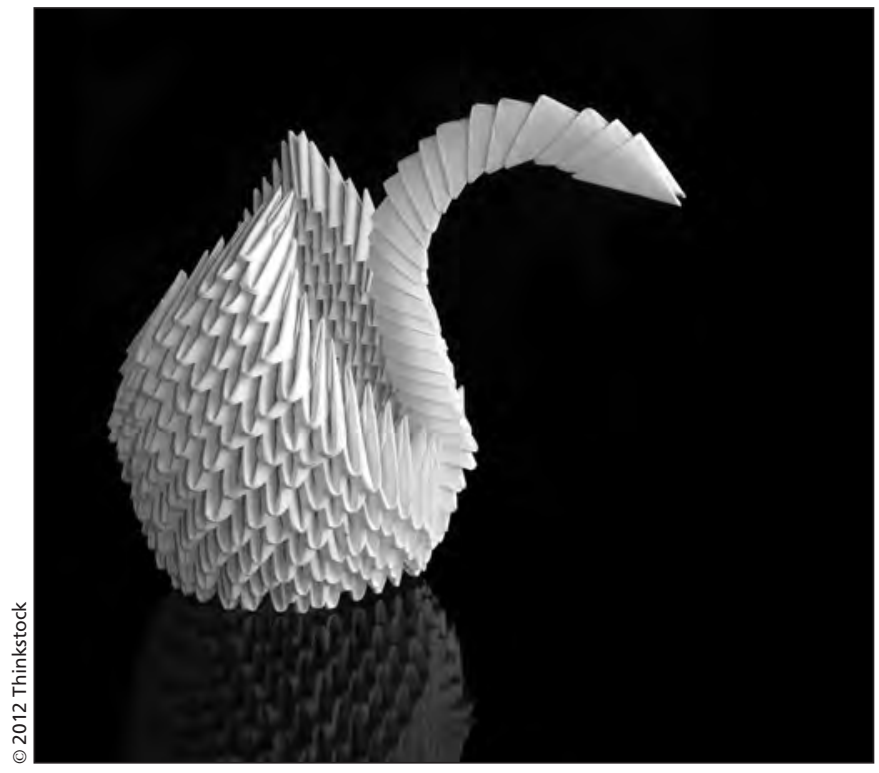

\section{"I am a doctor, and I write poems."}

Gunmetal Blue: A Memoir

Shane Neilson

Palimpsest Press; 2011.

I ' $m$ less familiar with guns than essays - initially I overlooked the graphic design on the cover of Shane Neilson's book, Gunmetal Blue: A Memoir. Then I read his opening essay, "Uncle Miltie and the locked ward." It's a harrowing account of his hospitalization for a suicidal psychosis.

The essay opened my eyes to the sepia-coloured specimens of brain and heart positioned like targets in the twin barrels of a shotgun - a visual compliment to poet Milton Acorn's The Brain's the Target. The cover's blueblack wash becomes the fathomless perimeter of a disordered mind in a hospital room: "The hospital was gunmetal blue: madhouses are best stark."

"I am a doctor, and I write poems," states Neilson on the final page of the book. That sounds more straightforward than it is. The practical demands of a life in medicine and the aesthetic realities of being a writer are not easily reconciled. Add to the work of poet and doctor the preoccupations of father, son and husband, and a man with a history of lifethreatening mental illness, and it gets even more complicated. He explains in the essay, "The Practice of Poetry": "I try to make sense of the world, of myself and others, and the major tool I use is poetry."

Neilson remembers that "[W]riting poems about medicine started out as an egocentric enterprise." One of his motives for going down the medical road: "I didn't want the life of the typical fulltime writer, dependent on dead end jobs and grants." That sounds a little dismissive of fellow writers whose life circumstances and career prospects may be different than his own. Neilson identifies more closely with the suffering than the starving artist. He acknowledges a special writerly debt to Acorn and Alden Nowlan, two of Canada's top tier, but also wounded, poets.

Many of the essays in Gunmetal Blue are illness narratives - his own and those of his patients. Neilson also repeatedly makes his case for the legitimacy of the literary arts, especially poetry, in the training and life of doctors. He describes the traps and disappointments - and rewards - inherent in writing. Along the way he draws inspiration and bolsters his observations and arguments with references to the work of many other writers.

According to Neilson, "[T]he real benefit of medicine [is] immersion in people's lives by choice."

Gunmetal Blue may be signalling a career transition for the author. Neilson contemplates writing a novel - about "love as an enormous yes, and death as its counter, but with failure as the final word." As much as I look forward to that book, it is the possibility of Neilson's subsequent work - beyond doctors and patients - that intrigues me even more.

\section{Vincent Hanlon MD}

Physician and Family Support Program Alberta Medical Association Calgary, Alta.

CMAJ 2012. DOI:10.1503/cmaj.120299 